\title{
Review of Kate Raworth's Doughnut Economics. London: Random House, 2017, 373 pp.
}

\section{ERIK SCHOKKAERT}

KU Leuven

Towards the end of her stimulating and thought-provoking book, Kate Raworth summarizes her main message as follows:

The twenty-first-century task is clear: to create economies that promote human prosperity in a flourishing web of life, so that we can thrive in balance within the Doughnut's safe and just space. It starts with recognizing that every economy - local to global - is embedded within society and within the living world. It also means recognizing that the household, the commons, the market and the state can all be effective means of provisioning for our many needs and wants, and they tend to work best when they work together. By deepening our understanding of human nature we can create institutions and incentives that reinforce our social reciprocity and other-regarding values, rather than undermine them. Once we accept the economy's inherent complexity, we can shape its ever-evolving dynamics through smart stewardship. That opens up the possibility of turning today's divisive and degenerative economies into ones that are distributive and regenerative by design. And it invites us to become agnostic about growth, creating economies that enable us to thrive, whether or not they are growing. (287)

This quote refers to the seven new ways of thinking about economic reality and about economic science that are developed in the book. The first way is the need to change the goal of the economy: rather than being fixated on GDP as a measure of social progress, humanity should focus on creating a social foundation of well-being that no one should fall below and an ecological ceiling of planetary pressure that the economy should not go beyond. Between the social foundation and the planetary ceiling lies the safe and just space for humanity, which she conceives to be a regenerative and redistributive economy. This vision of a better world is represented by the image of what looks like a doughnut: 


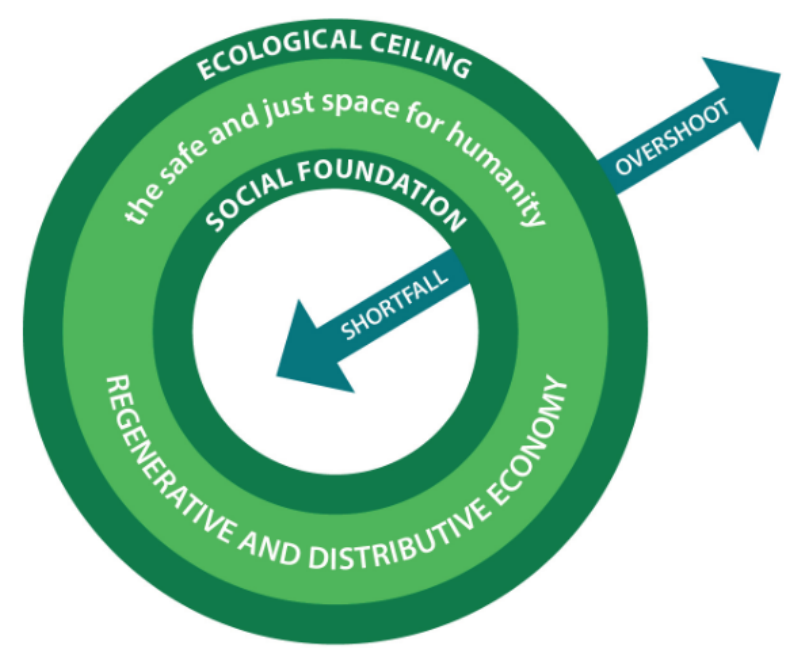

Inspired by this vision, Raworth then puts forward six additional ways of thinking like a twenty-first-century economist (as she calls it): (ii) to go beyond the market and understand the important role played by the state, the households, the commons; (iii) to realize that economic agents are not only driven by narrow economic self-interest, but are social and interdependent human beings; (iv) to take into account that the economy should not be modeled as a system in mechanical equilibrium, but as a complex dynamic system with feedback loops and tipping points; (v) to see economic inequality not as an unavoidable feature of the economic system, but as a design failure that can be repaired; (vi) to accept that the ecological boundaries impose on us the need to build a regenerative circular economy; and (vii) to discover how the economy can overcome its addiction to growth.

I agree with Raworth's core message as summarized by the seven points above. I am firmly at her side when she describes what a good society consists in. I also agree of course that there is a deep gulf between this vision of how a good world should look like, and the present situation of the real world. She provides compelling arguments to show the absurdities that characterize our present economic system, i.e. the large and unacceptable inequalities, the exaggerated focus on material consumption (and GDP growth), and the lack of respect for the constraints imposed by our living planet.

From the point of view of economics as a science, the challenge raised by the doughnut economy is then to analyze the mechanisms that have brought humanity in the present situation, and the institutional changes that are necessary in order to bring us on a better development 
path. This general challenge indicates a number of more specific issues. For example, which measure of well-being should replace GDP? How should we manage the commons? How can we set up a democratic state that is not lobbied by big firms? How should institutions and incentive structures that reinforce our social reciprocity look? How should we organize an open source system without destroying incentives for innovation? How can we bring about more international coordination between sovereign countries in the face of climate change, and the obvious problems of free ridership in the actual negotiations? How should we design and implement a "global tax on extreme personal wealth" (200)? How can we guarantee to all world citizens a decent level of material consumption, while at the same time respecting the physical boundaries of the earth? I had hoped that the book would go deeply into these many difficult issues. Unfortunately, it does not.

As the quote in the introduction illustrates, Raworth does emphasize that 'we' can change the world, that 'we' should build a more democratic, and a more sustainable economy, that 'we' should be less motivated by GDP-growth. Yet, it is not always clear who 'we' is, and it is even less clear how 'we' should realize all this. To be fair, Raworth gives a number of inspiring examples of social experiments in different parts of the world; but these social experiments are limited in size and scope. This raises the question: why have these experiments remained so limited? How can 'we' move beyond the creation of a set of small beautiful islands in an ugly world? To answer this question, academics should analyze the basic mechanisms underlying our economic and social system. Raworth does not offer such an analysis. Rather, she suggests an explanation of sorts: the main cause of global injustices and environmental degradation is that we have bad economics. Mainstream economics is the culprit. One should note that the title of the book does not refer to the need for a doughnut economy, but to the need for doughnut economics.

This explanation is not very credible. I do not think that anybody really believes that the influence of economic ideas can be so big as to explain everything that goes wrong in the world. It is true that simplistic ideas may be very influential in social debates, and that flawed economic reasoning is used and misused by people in power, such as politicians, business persons, and climate deniers, to defend the status quo. It is therefore true that it is necessary to fight this flawed economics. However, my contention is that good mainstream economics 
is one of the best instruments to correct these wrong arguments. The target of Raworth's criticism is not real mainstream economics, but a caricature of it. To some extent her position is understandable as the dominant view in many handbooks of economics unfortunately is close to the caricature (I return to this point below).

One of Raworth's tricks to denounce the mainstream is to define all interesting economists as non-mainstream (even if they are affiliated to traditional top economics departments and have been awarded the Nobel Memorial Prize in Economics like Kahneman, Sen, Deaton, Thaler, Stiglitz, and Ostrom). Some of the contributions she describes as influential (the flow model in macroeconomics, the stages of Rostow) were explained to me as a student in the 1970's, and already then presented as relics from the past-and her claim that the simple model of rational economic man is not questioned by mainstream economists nowadays is utterly surprising for everybody who really follows the recent developments in economics. Raworth is very keen to applaud the fact that critical students from the Kick Over movement plastered accusatory posters in the Boston Hotel where the "highbrow" (her formulation, 3) conference of the American Economic Association's annual 2015 meeting took place. According to Raworth, these posters denounced the "gulf between the preoccupations of mainstream economic theory and growing real-world crises such as global inequality and climate change" (1). But did she check what was on the program of that conference? The proceedings (published in the 'highbrow' American Economic Review of May 2015) show that the keynote by Raj Chetty was on "Behavioral Economics and Public Policy", and that there were sessions devoted to Thomas Piketty's Capital in the Twenty-First Century; impacts of the great recession on low-income households; high stakes energy and environmental problems in developing countries; empirical climate economics; culture, trust, and productivity; moral values and economic behavior; behavioral economics in the classroom; social behavior in the field; measuring the multinational economy; education, race, and underrepresented minorities; the economics of gender. Apparently, many economists do attempt to bridge the gulf between economic theory and real-world issues.

It may look overly defensive and even a bit childish for a mainstream economist to complain about Raworth's biased presentation of what mainstream economists are doing. Yet, I will argue that there is indeed a deep problem here. 
First, one can reasonably defend the position that, while it is silly to deny that economists are concerned with real world problems, there are still important flaws in economic methodology. Importantly, most economists give scant attention to natural resource constraints. There is certainly room for a serious debate on the strengths and limitations of methodological individualism, related to a discussion about the pros and cons of complexity dynamics (without a well specified behavioral model). However, nothing of this is found in the book. From the point of view of changing economics itself, constructing and attacking a straw man is not at all productive.

Second, and perhaps more relevant to Raworth's purpose, there is the important question of why primitive economic ideas about the optimality of markets and the need of GDP growth (or, even worse, the use of GDP as an indicator of well-being) have become so influential in the real world. Why are activists like Raworth so often confronted with single-minded economists objecting with overly simplistic arguments to the points raised in the citation with which I started this review? In fact, why are the basic handbooks of economics still dominated by these simple ideas? Of course, the debate within the discipline to some extent reflects ideological differences, and economists in general are likely to have a conservative bias. I understand and share Raworth's frustrations and her strong feelings about arrogant and myopic economists in power. However, I think that there is a more fundamental cause underlying this phenomenon.

In my view, already from its very beginning, economics has always been characterized by a confusing mixture of normative and positive considerations. This was certainly true for the classical economists, for the Marxians, for the marginal revolution, for Keynesianism, and for the new classical macroeconomics. It is a fascinating intellectual question how an apparently unregulated market economy does not collapse. It is therefore interesting to look at the features of what is called a general equilibrium. Yet, it is a further step to claim that under a set of (unrealistic) assumptions that general equilibrium is Pareto-optimal. And, it is an even further step to forget about the unrealistic assumptions that give rise to the a priori conviction that the unregulated market outcomes are socially desirable. This approach begs deep normative questions on the status of individual preferences as a criterion for the evaluation of economic outcomes. Moreover, it leads to the view that externalities are the exception rather than the rule, and 
that intervening in the market leads to harmful 'distortions'. It is this set of convictions that is still reflected in many (most) standard principles courses. And it is this set of convictions that indeed should be questioned-as Raworth does.

Yet, the research frontier in economics has obviously moved beyond these simple statements. The world of mainstream economics is now a world of behavioral agents in imperfect market settings who are influenced by non-monetary considerations. In fact, one of the good developments in recent mainstream economics is that it has become more empirically oriented. Of course, Raworth is right that the conservative bias is still strong; but, the economic toolbox has become much richer than it used to be in the past, and it can now be very helpful to better understand the mechanisms that are at work in the real world.

My main problem with Raworth's book is that it suffers from the same deep problem that has plagued economics from the beginning: an unfortunate and confusing mixture of positive and normative considerations. Most of her policy prescriptions are based on beliefs, hopes, and convictions, rather than on serious empirical analysis. Rather than giving new insights, she proposes a set of beliefs to counter another set of beliefs. Raworth's book is an important contribution to the ideological struggles about what is a good economy. It is a convincing competitor for handbook economics; but, despite its title it is not very helpful for those who want to build an attractive empiricallyoriented doughnut economics.

I think this is highly problematic-both for handbook and for doughnut economics. Let me return to the issues mentioned at the start of this review. It is true that individuals may be altruistically motivated, that they are not exclusively motivated by financial self-interest, and that reciprocity is an important motivation-but, it would be very dangerous to assume that this is always the case and to completely neglect the presence of self-interested free riders. It is true that the power of the commons has been underrated by many economists-but, serious questions remain about the way to handle these commons. It is true that the traditional anti-state and pro-market bias of many economists is a very unfruitful attitude in the light of the great challenges before us-but, the state can also be an instrument of the powerful and the rich to exploit the poor, and the design of democratic institutions is not straightforward, certainly not at the global level. It is 
true that economic inequality in the present world is unacceptable, and that it is essential to shift attention from purely redistributive measures to the mechanisms determining the primary distribution of incomebut, much more work is needed to better understand the pitfalls in the move to such a more democratic economy. It is true that we should steer innovation and research so that they can contribute to a more just, and a more durable economy-but, steering innovation and research is far from trivial. And all these challenges become even more acute when we fully take up the resource constraints facing humankind.

If we want a better world, we certainly have to go beyond the market and growth ideology of many economists now. But it is equally important to go beyond simple activist beliefs in a new world. Activism is important, but it may also be dangerous. I fully side with Raworth's claims about what would be a good economy. I think however that the transition towards such a good economy will not be easy and that detailed design issues are crucially important. Mainstream economics certainly will not give the one and only definitive answer, but it offers a coherent framework to tackle some of the main problems with the transition. Rather than construct a 'mainstream' strawman and kill it, it would be far more reasonable to try to establish a coalition with real 'mainstream' economists who agree with her basic views: that the model of the market has to be embedded in a broader view of society, that the economy should take into account resource constraints, that the distribution of economic resources reflects to some extent inequalities in power, that human beings are not only calculators driven by economic self-interest, but have broader values in life and imperfect decision-making capacities. All these perspectives are present in mainstream economics.

Raworth's extremely well-written book has been influential in proposing the idea of the doughnut economy. That is fine: the more people are convinced that the economy has to be put on a different development path, the better. It is also effective in showing that the simplistic conservative interpretation, and abuse of some economic insights, is dangerous. That is another good thing. Yet, it aims at the wrong target by discarding all insights from modern mainstream economics-in fact, it simply does not mention any of these insights. At that point, it becomes more of a sermon than an analysis. This is a missed opportunity. 
Erik Schokkaert is full professor of welfare economics at the Department of Economics of the KULeuven. He has been visiting professor at the London School of Economics, the Université catholique de Louvain and the Universidad ICESI in Cali. His research focuses on (i) the modelling of different notions of distributive justice; (ii) the concept of individual well-being and quality of life; (iii) the application of these concepts to the analysis of specific policy problems in the fields of health, social security, and taxation. He has published in (among others) American Economic Journal: Microeconomics, Demography, Rand Journal of Economics, Journal of Health Economics, Health Economics, Journal of Public Economics, Social Choice and Welfare, Economics and Philosopy, European Economic Review, Health Policy, and Economica. Together with Wulf Gaertner he has written a book on Empirical Social Choice: Questionnaire-Experimental Studies on Distributive Justice (Cambridge University Press, 2012).

Contact e-mail: <erik.schokkaert@kuleuven.be> 